\title{
Descumprimento do contrato de estágio e a caracterização do vínculo empregatício
}

\author{
Breach of the internship contract and the characterization of the employment relationship
}

\author{
Letícia Caroline Braga ${ }^{1}$ (iD), Everaldo da Silva ${ }^{2}$ (iD) e Wellington Lima Amorim ${ }^{3}$ (iD \\ ${ }^{1}$ Centro Universitário de Brusque (UNIFEBE), especialista em Direito do Trabalho e Previdenciário (UNIFEBE), \\ email: leticiacbraga@outlook.com \\ ${ }^{2}$ Secretaria de Estado da Educação (SED/SC), doutor em Sociologia Política, email: prof.evesilva@gmail.com \\ ${ }^{3}$ Universidade Federal do Rio Grande do Sul (UFRGS), doutor em Ciências Humanas, pós-doutor em Filosofia e \\ Desenvolvimento Regional, email: wellington.amorim@gmail.com
}

\section{RESUMO}

Este artigo tem como tema principal o descumprimento do contrato de estágio, conhecido pela lei $\mathrm{n}^{\circ}$ 11.788/2008, e a consequente caracterização do vínculo empregatício, tratando como fraude o desvirtuamento das cláusulas firmadas no termo de compromisso. A celebração do contrato de estágio ocorre entre três componentes, sendo o educando, a unidade concedente do estágio e a instituição de ensino, cabendo a esta tripartite cumprir e atentar-se pela legalidade desta modalidade de trabalho. Neste sentido, a pesquisa tem como objetivo conceituar estágio, demonstrar seus requisitos, conhecer algumas jurisprudências favoráveis e controvérsia deste tema, além de analisar o atual cenário à luz da Lei do Estágio. O método de pesquisa utilizado foi o dedutivo, além do aprofundamento bibliográfico, partindo do estudo à legislação, pensamentos de doutrinadores e decisões encontradas na jurisprudência. As fraudes existem e são corriqueiras, levando ao entendimento de que a Lei do Estágio não está em funcionamento legal como deveria, cabendo maior atenção dos órgãos fiscalizadores de forma a contribuir para o crescimento profissional dos educandos que optam por este caminho, zelando pela manutenção da lei e o bom relacionamento entre as partes. A legislação cita em seus artigos a importância e responsabilidade de todo o processo para as instituições de ensino, empresas que concedem a oportunidade de estágio e ao estudante, bem como também abordam os doutrinadores, pois não trata-se de uma atividade simplesmente profissional, mas também pedagógica e prática.

Palavras-chave: Estágio. Vínculo empregatício. Contrato de estágio. Legislação.

\begin{abstract}
The main theme of this article is the non-fulfillment of the internship contract, known by law no. $11.788 / 2008$, and the consequent characterization of the employment relationship, treating as fraud the distortion of the clauses signed in the commitment term. The signing of the internship contract occurs between three components, being the student, the unit granting the internship and the educational institution, and it is up to this tripartite to comply and pay attention to the legality of this type of work. In this sense, the research aims to conceptualize internship, demonstrate its requirements, know some favorable jurisprudence and controversy on this topic, and analyze the current scenario in light of the Internship Law. The research method used was the deductive one, in addition to the bibliographic deepening, starting from the study to the legislation, thoughts of doctrinators and decisions found in the jurisprudence. Frauds exist and are commonplace, leading to the understanding that the Internship Law is not in legal operation as it should be, and that greater attention should be paid to the inspection bodies in order to contribute to the professional growth of students who choose this path, ensuring the maintenance of the law and the good relationship between the parties. The legislation cites in its articles the importance and responsibility of the entire process for educational institutions, companies that grant the opportunity of internship and the student, as well as also address the doctrinators, because it is not simply a professional activity, but also pedagogical and practical.
\end{abstract}

Keywords: Internship. Employment relationship. Internship contract. Legislation. 


\section{INTRODUÇÃO}

Todo jovem estudante que almeja ingressar no mercado de trabalho em sua área de formação, busca por alguma oportunidade dentro das condições legais e temporais, levando em consideração de que, por muitas vezes, não possui tempo disponível para conciliar os estudos e o trabalho. A concorrência por vagas disponíveis nas mais variadas áreas de formação é vasta, porém muitos empregadores, além de buscar pessoas que tenham formação educacional, também optam pelo candidato que possua alguma experiência no serviço ofertado. O estágio curricular, disponibilizado pela Lei do Estágio - lei no 11.788/2008, é de suma importância ao jovem que se encaixa nas condições de estudante que, dentro do cenário atual, busca a inserção ao mercado de trabalho.

As instituições de ensino possuem dentro de cada curso ofertado um plano pedagógico que proporciona esta introdução do educando ao mundo profissional, de forma a contribuir com o aprendizado dos alunos e a sociedade empresarial. Para o estudante que tem a possibilidade de ingressar em uma empresa, atuando em sua área de estudo, o estágio se destaca por agregar valor ao seu currículo, pois cumprindo a grade curricular alinhado a prática empresarial, o jovem desenvolve novas habilidades e qualificações, além de todo o conhecimento que levará consigo em sua jornada profissional.

As organizações que concedem vagas de estágio se beneficiam de diversas formas, pois desenvolver um programa de estágio dentro da empresa pode acarretar em vantagens competitivas, além do empregador ser bem visto perante a sociedade, por proporcionar aos jovens estudantes o ingresso ao mundo profissional. Com base na atual Lei do Estágio, $\mathrm{n}^{\circ} 11.788$, que tornou-se vigente em 2008, as responsabilidades desta tripartite (instituição de ensino, educando e empresa concedente) são expostas, mediante a celebração de um termo de compromisso, sendo obrigatório cumprir cada cláusula, com o risco do não cumprimento caracterizar relação de emprego entre o jovem estagiário e a empresa concedente.

Levando em consideração a tantos benefícios que a lei $\mathrm{n}^{\circ}$ 11.788/2008 traz a realidade dos estudantes, empresas e instituições de ensino, como pode haver fraude nesta relação e trabalho, infringindo a lei e causando caracterização de vínculo empregatício? No acordo tripartite há beneficiários com a relação fraudulenta? O descumprimento Lei do Estágio ocorre, mais precisamente, acerca do termo de compromisso, quando o mesmo não é respeitado, corrompendo o plano pedagógico do curso, burlando as normas legais, colocando em risco as atividades e 
desempenho do estagiário, além da caracterização de vínculo empregatício, anulando a lei $\mathrm{n}^{\circ}$ 11.788/2008 e passando a seguir o Decreto-Lei n ${ }^{\circ} 5.452 / 43$, mais conhecido por Consolidação das Leis do Trabalho (CLT).

Pode ser percebido no presente artigo a distinção entre relação de trabalho e a relação de emprego, os direitos e deveres que a Lei do Estágio aborda em seu texto, além da exposição dos pontos de vista de doutrinadores e das decisões judiciais sobre o tema, buscando o entendimento em relação ao descumprimento da lei e suas consequências. Iniciamos esta pesquisa abordando um breve histórico da Lei do Estágio, relacionando suas mudanças no passar dos anos, até chegarmos à lei atual, vigente desde 2008. Atrelado a isto, o artigo trata mais precisamente sobre a finalidade do contrato de estágio e seus requisitos jurídicos, citando pensamentos de distintos doutrinadores e posições jurisprudenciais, já que o tema é discutido nos tribunais de forma tão habitual. Para alinhar as informações contidas neste artigo foi utilizado o método dedutivo, se tratando de conceitos empregados em diversas áreas de estudo, relacionando as mais variadas formas de raciocínio, chegando ao conhecimento verdadeiro da questão. Como classificação da pesquisa bibliográfica, buscamos orientações em livros, artigos, doutrinas e leis, atentos as soluções do tema proposto.

Primeiramente analisamos as leis, de acordo com suas mudanças ao passar dos anos, levando em consideração cerca de seis décadas (1940 - 2000), para chegar a lei atual, nº 11.788 , sancionada em 2008. Cada Lei do Estágio contribuiu com melhorias para que a lei vigente fosse melhor interpretada, com o intuito de maior fiscalização, visando a fidelidade em seu cumprimento e evitando possíveis fraudes. De acordo com lei atual, observamos que muitos doutrinadores têm entendimentos semelhantes perante o cumprimento do termo de compromisso e a relação estreita entre estagiário e empregado.

A CLT - Consolidação das Leis do Trabalho aborda pontos primordiais a seguir na relação de emprego, bem como a lei n ${ }^{\circ} 11.788 / 2008$ é transparente perante os estagiários, para que não se confundam entre si. Em pesquisa a precedentes jurídicos, as jurisprudências apontam que há fraudes relacionadas ao desvirtuamento do contrato de estágio, como também há validade em contratos celebrados, geralmente confirmados por falta de provas. Conforme o estudo do presente artigo nota-se a abertura ao descumprimento do contrato de estágio quando a Lei do Estágio traz o regulamento, contudo muito próximo a realidade de empregado, regido pela CLT, bem como citam as doutrinas e as comprovações pelos julgamentos. 


\title{
2 BREVE HISTÓRICO SOBRE A CRIAÇÃO DA LEI DO ESTÁGIO
}

A Lei $n^{\circ}$ 11.788, sancionada em 25 de setembro de 2008, passou a vigorar no Brasil com o objetivo de regulamentar e dispor condições legais aos educandos que buscam a carreira profissional, porém não possuem nenhuma experiência neste âmbito. No Brasil as mudanças relativas ao conceito de estágio ocorreram a fim de acompanhar a evolução legislativa educacional. No passar dos anos houve muitos debates na esfera jurídica sobre o estágio, pois havia confrontos de interesses entre escola e empresários, estes que são pilares perante o contrato de estágio. Muitas normas, decretos e Leis já regulamentaram o estágio, levando em consideração preceitos desde a década de 1940 até os dias atuais, com a lei nº 11.788/2008, observando alguns avanços e certas barreiras nas implementações e expectativas sobre o tema, além do crescimento no processo didático-pedagógico como base curricular.

\begin{abstract}
A legislação instituidora e regulamentadora desse tipo legal examinado foi, por longo tempo, a Lei n. 6.494, de 1977, que sofreu diversas alterações nas décadas seguintes, e seu regulamento normativo, Decreto n. 87.497, de 1982, com subsequentes modificações. Tal legislação regulava o estágio em geral, ficando reservada a diplomas específicos a normalização de estágios relativos a certas profissões legalmente reguladas (Advocacia, Medicina, etc.). (DELGADO, 2013, p. 317).
\end{abstract}

Contudo, não somente com o objetivo de dar providências, a lei no 11.788/2008, alterou a redação do art. 428 da Consolidação das Leis do Trabalho (CLT), a qual aborda orientações regulamentares a respeito da validação dos contratos, tempo o qual será destinado a esta modalidade, ademais direitos e obrigações das partes envolvidas, bem como instituição de ensino, empresa concedente e educando, sendo aprovada pelo Decreto-Lei $\mathrm{n}^{\circ} 5.452$, de $1^{\circ}$ de maio de 1943 , e a lei $\mathrm{n}^{\circ}$ 9.394, de 20 de dezembro de 1996. Da mesma forma, a lei vigente revogou as leis $\mathrm{n}^{\mathbf{o}}$ 6.494, de 7 de dezembro de 1977, e $\mathrm{n}^{\circ}$ 8.859, de 23 de março de 1994, além do parágrafo único do art. 82 da lei $n^{\circ} 9.394$, de 20 de dezembro de 1996, e o art. $6^{\circ}$ da Medida Provisória $n^{\circ} 2.164-41$, de 24 de agosto de 2001, todos relacionados aos direitos e deveres no contrato de estágio. Em suma, seis décadas (1940 - 2000) passaram-se e muito se foi alterado, visando melhorias entre leis, decretos, portarias e decisões que expandiram o conceito de estágio até a lei vigente, sancionada em 2008. 


\section{FINALIDADE DO CONTRATO DE ESTÁGIO E SEUS REQUISITOS JURÍDICOS À LUZ DA LEI N 11.788/2008}

O estágio curricular tornou-se uma porta aberta ao mundo profissional, sendo o primeiro contato entre o estudante e a carreira escolhida. Nesta fase, o educando tem a oportunidade de adquirir experiência com a rotina empresarial, além de colocar em execução o quem vem estudando, empregando seus conhecimentos com a junção de teoria e prática, visando bons relacionamentos e crescimento dentro do ambiente profissional. Trata-se de um ato educativo escolar supervisionado, ou seja, com acompanhamento profissional, desenvolvido para preparar o educando a vida cidadã e ao mercado de trabalho, bem como estabelece o art. $1^{\circ}$ da lei atual:

\footnotetext{
Art. 1o Estágio é ato educativo escolar supervisionado, desenvolvido no ambiente de trabalho, que visa à preparação para o trabalho produtivo de educandos que estejam frequentando o ensino regular em instituições de educação superior, de educação profissional, de ensino médio, da educação especial e dos anos finais do ensino fundamental, na modalidade profissional da educação de jovens e adultos.

$\S 1$ o $\mathrm{O}$ estágio faz parte do projeto pedagógico do curso, além de integrar o itinerário formativo do educando.

$\S 2$ o $\mathrm{O}$ estágio visa ao aprendizado de competências próprias da atividade profissional e à contextualização curricular, objetivando o desenvolvimento do educando para a vida cidadã e para o trabalho. (BRASIL, 2008, p. 01)
}

Quando firmado, o contrato de estágio poderá ser tanto obrigatório quanto não obrigatório, pois transcorrerá de acordo com as diretrizes curriculares desta etapa, além da modalidade, área de ensino e projeto pedagógico de cada curso, como cita o art. $2^{\circ}$ da Lei do Estágio (nº 11.788/2008). Portanto, será de forma obrigatória quando definido como tal no projeto do curso, sendo necessário cumprir carga horária para aprovação e obtenção do diploma, e não será obrigatório quando forem desenvolvidas como atividade opcional, como acréscimo as horas regulares e obrigatórias do curso (BRASIL, 2008, p. 01). Para firmar o contrato de estágio é necessário atentar-se a alguns requisitos legais e indispensáveis, tais como matrícula e frequência escolar do educando, acompanhamento efetivo, celebração do termo de compromisso e compatibilidade entre as atividades desenvolvidas no estágio e as firmadas no mencionado termo de compromisso. O termo de compromisso, celebrado entre educando, parte concedente do estágio e instituição de ensino, é essencial tanto no estágio curricular obrigatório quanto no estágio não obrigatório. Sendo um acordo tripartite, o termo deve conter todas as cláusulas que nortearão o 
contrato, tal como prevê a Cartilha Esclarecedora da Lei do Estagio, disponibilizada pelo Ministério do Trabalho e Emprego (2008):

a) dados de identificação das partes, inclusive cargo e função do supervisor do estágio da parte concedente e do orientador da instituição de ensino;

b) as responsabilidades de cada uma das partes;

c) objetivo do estágio;

d) definição da área do estágio;

e) plano de atividades com vigência; (parágrafo único do art. $7^{\circ}$ da Lei $n^{\circ} 11.788 / 2008$ );

f) a jornada de atividades do estagiário;

g) a definição do intervalo na jornada diária;

h) vigência do Termo;

i) motivos de rescisão;

j) concessão do recesso dentro do período de vigência do Termo;

k) valor da bolsa, nos termos do art. 12 da Lei ${ }^{\circ}$ 11.788/2008; Cartilha Esclarecedora sobre a Lei do Estágio - Lei no 11.788/2008

1) valor do auxílio-transporte, nos termos do art. 12 da Lei n ${ }^{\circ} 11.788 / 2008$;

m) concessão de benefícios, nos termos do $\S 1^{\circ}$ do art. 12 da Lei $n^{\circ} 11.788 / 2008$;

n) o número da apólice e a companhia de seguros. (BRASILIA, 2008, p. 17-18).

Em referência a lei $\mathrm{n}^{\circ} 11.788 / 2008$, apresenta-se os seguintes requisitos mediante as obrigações da instituição de ensino:

Art. 7o São obrigações das instituições de ensino, em relação aos estágios de seus educandos:

I - celebrar termo de compromisso com o educando ou com seu representante ou assistente legal, quando ele for absoluta ou relativamente incapaz, e com a parte concedente, indicando as condições de adequação do estágio à proposta pedagógica do curso, à etapa e modalidade da formação escolar do estudante e ao horário e calendário escolar;

II - avaliar as instalações da parte concedente do estágio e sua adequação à formação cultural e profissional do educando;

III - indicar professor orientador, da área a ser desenvolvida no estágio, como responsável pelo acompanhamento e avaliação das atividades do estagiário;

IV - exigir do educando a apresentação periódica, em prazo não superior a 6 (seis) meses, de relatório das atividades;

$\mathrm{V}$ - zelar pelo cumprimento do termo de compromisso, reorientando o estagiário para outro local em caso de descumprimento de suas normas;

VI - elaborar normas complementares e instrumentos de avaliação dos estágios de seus educandos;

VII - comunicar à parte concedente do estágio, no início do período letivo, as datas de realização de avaliações escolares ou acadêmicas.

Parágrafo único. O plano de atividades do estagiário, elaborado em acordo das 3 (três) partes a que se refere o inciso II do caput do art. 3o desta Lei, será incorporado ao termo de compromisso por meio de aditivos à medida que for avaliado, progressivamente, $o$ desempenho do estudante. (BRASIL, 2008, p. 2).

Na teoria de Martinez (2012, p. 110) "retira a validade de contrato de estágio que não tenham sido celebrados mediante o referido termo de compromisso. Assim, se não há o termo de compromisso, não há contrato de estágio". Ressalta-se porém a faculdade de celebração do 
convênio de concessão de estágio com entes públicos e privados, exaltando o processo pedagógico e não dispensando a celebração do termo de compromisso entre as partes. São obrigações da empresa, apresentada como parte concedente do estágio:

Art. $9^{\circ}$ As pessoas jurídicas de direito privado e os órgãos da administração pública direta, autárquica e fundacional de qualquer dos Poderes da União, dos Estados, do Distrito Federal e dos Municípios, bem como profissionais liberais de nível superior devidamente registrados em seus respectivos conselhos de fiscalização profissional, podem oferecer estágio, observadas as seguintes obrigações:

I - celebrar termo de compromisso com a instituição de ensino e o educando, zelando por seu cumprimento;

II - ofertar instalações que tenham condições de proporcionar ao educando atividades de aprendizagem social, profissional e cultural;

III - indicar funcionário de seu quadro de pessoal, com formação ou experiência profissional na área de conhecimento desenvolvida no curso do estagiário, para orientar e supervisionar até 10 (dez) estagiários simultaneamente;

IV - contratar em favor do estagiário seguro contra acidentes pessoais, cuja apólice seja compatível com valores de mercado, conforme fique estabelecido no termo de compromisso;

V - por ocasião do desligamento do estagiário, entregar termo de realização do estágio com indicação resumida das atividades desenvolvidas, dos períodos e da avaliação de desempenho; de estágio;

VI - manter à disposição da fiscalização documentos que comprovem a relação

VII - enviar à instituição de ensino, com periodicidade mínima de 6 (seis) meses, relatório de atividades, com vista obrigatória ao estagiário.

Parágrafo único. No caso de estágio obrigatório, a responsabilidade pela contratação do seguro de que trata o inciso IV do caput deste artigo poderá, alternativamente, ser assumida pela instituição de ensino. (BRASIL, 2008, p. 3).

Além das obrigações citadas, Delgado (2013, p. 319-320) expõe em suas doutrinas pontos fundamentais que reiteram a validade do contrato de estágio, bem como consta lei $\mathrm{n}^{\circ}$ 11.788/2008, se tratando do labor e seus limites temporais, saúde e segurança no trabalho, o devido acompanhamento ao estagiário e também a inclusão social e a possibilidade de estudantes estrangeiros aderirem a esta oportunidade de inserção ao mercado de trabalho no Brasil. O estágio, em sua nova caracterização conforme a lei vigente, é definido por limites em suas jornadas de trabalho, sendo de forma padrão por 4 (quatro) horas diárias e 20 (vinte) semanais (para educandos matriculados na educação especial ou nos anos finais do ensino fundamental); por 6 (seis) horas diárias e 30 (trinta) semanais (para educandos do ensino superior ou da educação profissional de nível médio e do ensino médio regular); duração do estágio de até 2 (dois) anos, sem exceder, na mesma parte concedente, exceto nos casos de estagiário portador de deficiência. (BRASIL, 2008, p. 03 apud DELGADO, 2013, p. 319-320). 
$\S 1^{\circ} \mathrm{O}$ estágio relativo a cursos que alternam teoria e prática, nos períodos em que não estão programadas aulas presenciais, poderá ter jornada de até 40 (quarenta) horas semanais, desde que isso esteja previsto no projeto pedagógico do curso e da instituição de ensino.

$\S 2^{\circ}$ Se a instituição de ensino adotar verificações de aprendizagem periódicas ou finais, nos períodos de avaliação, a carga horária do estágio será reduzida pelo menos à metade, segundo estipulado no termo de compromisso, para garantir o bom desempenho do estudante. (BRASIL, 2008, p. 3).

Se tratando de limitação, a parte concedente deve seguir as contratações de estagiários de acordo com a legislação (art. 17, lei n. 11.788/2008), bem como cita o doutrinador:

\begin{abstract}
A Lei limita o número de estagiários por empresa: de um a cinco empregados, um estagiário; de seis a dez, dois estagiários; de onze a vinte e cinco, cinco estagiários; acima de vinte e cinco, até $20 \%$ de estagiários, percentuais aplicáveis a cada unidade da empresa, limitações que não se aplicam aos estagiários de nível superior e de nível médio profissional. (NASCIMENTO A. M., NASCIMENTO S. M., 2014, p. 184)
\end{abstract}

Percebe-se que além da jornada de trabalho, o art. 14 da nova lei, aplica ao estagiário toda a legislação referente a saúde e segurança no trabalho, pelo tempo que durar o estágio, sendo a responsabilidade da parte concedente do estágio assegurá-lo. O descumprimento dos requisitos básicos ora mencionados ou de qualquer obrigação contida no termo de compromisso firmado entre as partes, caracterizará vínculo empregatício do educando com a parte concedente do estágio, gerando todos os direitos trabalhistas e previdenciários. Contudo, levando em consideração o ambiente de trabalho, mesmo o contrato de estágio não firmar nenhum vínculo empregatício, é comum notar certas características das Leis trabalhistas durante o desenvolvimento das atividades do educando, se tratando da modalidade de trabalho mais próxima a CLT.

Art. 12. O estagiário poderá receber bolsa ou outra forma de contraprestação que venha a ser acordada, sendo compulsória a sua concessão, bem como a do auxílio-transporte, na hipótese de estágio não obrigatório.

$\S 1^{\circ}$ A eventual concessão de benefícios relacionados a transporte, alimentação e saúde, entre outros, não caracteriza vínculo empregatício.

$\S 2^{\circ}$ Poderá o educando inscrever-se e contribuir como segurado facultativo do Regime Geral de Previdência Social. (BRASIL, 2008, p. 03)

A unidade concedente tem o poder de dirigir o comportamento do aluno e exigir o cumprimento das atividades dentro da empresa, mediante acompanhamento efetivo pelo professor orientador da instituição de ensino e também do supervisor encarregado de acompanhar o educando durante seu contrato com a parte concedente. 
Art. $3^{\circ} \mathrm{O}$ estágio, tanto na hipótese do $\S 1^{\circ}$ do art. $2^{\circ}$ desta Lei quanto na prevista no $\S 2^{\circ}$ do mesmo dispositivo, não cria vínculo empregatício de qualquer natureza, observados os seguintes requisitos:

I - matrícula e frequência regular do educando em curso de educação superior, de educação profissional, de ensino médio, da educação especial e nos anos finais do ensino fundamental, na modalidade profissional da educação de jovens e adultos e atestados pela instituição de ensino;

II - celebração de termo de compromisso entre o educando, a parte concedente do estágio e a instituição de ensino;

III - compatibilidade entre as atividades desenvolvidas no estágio e aquelas previstas no termo de compromisso

$\S 1^{\circ} \mathrm{O}$ estágio, como ato educativo escolar supervisionado, deverá ter acompanhamento efetivo pelo professor orientador da instituição de ensino e por supervisor da parte concedente, comprovado por vistos nos relatórios referidos no inciso IV do caput do art. 70-desta Lei e por menção de aprovação final.

$\S 2^{\circ}-\mathrm{O}$ descumprimento de qualquer dos incisos deste artigo ou de qualquer obrigação contida no termo de compromisso caracteriza vínculo de emprego do educando com a parte concedente do estágio para todos os fins da legislação trabalhista e previdenciária. (BRASIL, ano, p. 1).

Outra figura importante na relação de estágio é o agente de integração, sendo entidades públicas ou privadas que fazem a ligação entre a instituição de ensino e os setores que buscam estagiários, mediante acordo em instrumento jurídico adequado.

No exercício das atividades ora relacionadas, os agentes de integração serão responsabilizados civilmente se indicarem estagiários para a realização de atividades não compatíveis com a programação curricular estabelecida para cada curso, assim como estagiários matriculados em cursos ou instituições para as quais não haja previsão de estágio curricular. Caso a má intermediação do agente de integração gere a formação de vínculo de emprego, é razoável afirmar que lhe será atribuída responsabilidade solidária quanto ao pagamento dos créditos trabalhistas que haverão de ser assumidos pela concedente da oportunidade de estágio, tudo na forma do parágrafo único do art. 942, do Código Civil. (MARTINEZ, 2012, p. 114).

Quem concede o estágio tem a seriedade de orientar e supervisionar o que ocorre na prática, alinhando informações e formando uma base triangular, cabendo a empresa concedente, a instituição de ensino e o estagiário compor esta pirâmide, interligados por meio de relatórios periódicos e feedbacks referente a postura do educando em seu exercício.

\section{DISTINÇÃO ENTRE EMPREGO E ESTÁGIO}

De acordo com o texto da lei $n^{\circ} 11.788 / 2008$, o contrato de estágio não é caraterizado como relação de emprego e nem pode ser tratado desta forma, pois condiz a uma modalidade especial de inserção ao mercado profissional com objetivos pedagógicos.

Ciências Sociais Aplicadas em Revista, v. 20, n. 38, p. 60-77, semestral, janeiro-junho, 2020. 
O estagiário é o destinatário principal. É o estudante, que para complementar os seus estudos, o faz com a prática profissional o que o põe numa posição de identificação com os empregados de uma empresa, para que possa enfrentar as mesmas dificuldades e problemas. (NASCIMENTO A. M., NASCIMENTO S. M., 2014, p. 184).

Entretanto, na doutrina dos mesmos autores citados acima, esta distinção entre empregado e estagiário pode ocasionar equívocos no ato de uma fiscalização, sem perceber que o estágio, celebrado e regido por um termo de compromisso, só pode ser realizado pelo trabalho e que o trabalho também é realizado pelo empregado, este que é regido pela Consolidação das Leis do Trabalho (CLT). Ambos diferem-se apenas por uma questão de grau.

Art. 15. A manutenção de estagiários em desconformidade com esta Lei caracteriza vínculo de emprego do educando com a parte concedente do estágio para todos os fins da legislação trabalhista e previdenciária.

$\S 1^{\circ} \mathrm{A}$ instituição privada ou pública que reincidir na irregularidade de que trata este artigo ficará impedida de receber estagiários por 2 (dois) anos, contados da data da decisão definitiva do processo administrativo correspondente.

$\S 2^{\circ}$ A penalidade de que trata o $\S 1$ o deste artigo limita-se à filial ou agência em que for cometida a irregularidade. (BRASIL, 2008, p. 4).

Nas considerações referentes aos elementos que compõe a relação de emprego, caracterizando como empregado, Godinho (2013) enfatiza a CLT, apontando 5 componentes: a) a prestação de trabalho por pessoa física a um empregador qualquer; b) prestação efetuada com pessoalidade pelo trabalhador; c) também efetuada com não eventualidade; d) efetuada ainda sob subordinação ao tomador dos serviços; e) prestação de trabalho efetuada com onerosidade. Acerca dos componentes destacados pelo autor citado acima, os doutrinadores Nascimento A. M. e Nascimento S. M. (2014, p. 174), também relacionam estes pontos, em seus entendimentos, definidos pela Consolidação das Leis do Trabalho (CLT), do mesmo modo, sendo esta lei, presente no art. $2^{\circ}$ e $3^{\circ}$, como principal requisito legal; a pessoalidade, enfatizando que não pode haver contratação de uma pessoa jurídica, pois a proteção da lei é destinada ao ser humano; a continuidade, pois o empregado não é trabalhador eventual; a subordinação, aplicando a dependência como seu sinônimo, pois a atividade exercida é dependente de outrem para quem ela é dirigida. Do mesmo modo, vale ressaltar que o conceito de empregador vincula-se a "empresa, individual ou coletiva, que, assumindo os riscos da atividade econômica, admite, assalaria e dirige a prestação pessoal de serviços" (GODINHO, 2013, p. 282). 
A Lei do Estágio, por outro lado, não autoriza que pessoas físicas (entre as quais podem ser citados os empregadores domésticos, os condôminos e os empresários individuais pessoas físicas) sejam concedentes de oportunidade de estágio, ressalvadas apenas aquelas que tenham sido constituídas como "empresa individual de responsabilidade limitada" (EIRELI), nos termos da Lei n. 12.441, de 11 de julho de 2011. (MARTINEZ, 2012, p. 112).

A lei vigente do estagiário traz em sua redação tópicos que, mediante termo de compromisso, distanciam a possibilidade de caracterização de emprego, inclusive tratando de tempo de duração do contrato, quantidade de horas a cumprir e faculdade a respeito do recebimento de bolsa de estudo, ou qualquer outra contraprestação previamente acordada entre as partes, compulsória a sua concessão, como por exemplo, o recebimento de bolsa ou vale transporte no caso de estágio não obrigatório (BRASIL, 2008).

Haja vista, quando o legislador mencionou contraprestação de bolsa, talvez se denominou desta forma para que não houvesse duvidas nas relações, mesmo sendo compulsória, contudo esta denominação vem acarretar discussões jurídicas, pois para alguns doutrinadores o elemento salário abrange contraprestação. O estagiário e o empregado podem ter, desta forma, a mesma relação de trabalho, sendo que "o estágio traduz-se em um dos tipos de trabalhadores que mais se aproximam da figura jurídica do empregado - sem que a legislação autorize, porém, sua tipificação como tal” (DELGADO, 2013, p. 316). Respeitando os termos acordados e distanciando a característica de vínculo empregatício, o estágio, de forma correta e fiel ao objetivo educacional, não pode ser tratado como relação de emprego, contudo há muita discussão na esfera jurídica sobre este tema.

\subsection{ENTENDIMENTO DOS TRIBUNAIS}

Observando as diretrizes da Lei do Estágio n. 11.788/2008 e o posicionamento de alguns doutrinadores, os tribunais vem analisando este tema, observando cada caso concreto, decidindo ora pela caracterização da relação de emprego, tornando nulo o contrato de estágio, ora firmando a relação de estágio, afastando o vínculo empregatício. Com o intuito de expor algumas decisões, ver-se-á os julgados a favor e contrários ao reconhecimento do vínculo empregatício, havendo ou não o desvirtuamento na relação de estágio. Quando ocorre a descaracterização da relação de estágio, firmando o vínculo empregatício, é imprescindível que o empregador que arque com todas as verbas previdenciárias e trabalhistas relativas a esta espécie de contrato. 
VÍNCULO DE EMPREGO. ÔNUS DA PROVA. CONTRATO DE ESTÁGIO. O ônus da prova quanto à existência de relação empregatícia impõe que o trabalhador comprove a prestação de serviços em favor do suposto empregador e, quando incontroversa ou comprovada a prestação de serviços, cabe à alegada empregadora demonstrar que a relação havida não foi de vínculo empregatício, nos termos do art. 818 da CLT, combinado com art. 373, I e II, do CPC/2015. Ausência de comprovação do preenchimento dos requisitos da Lei $\mathrm{n}^{\circ} 11.788 / 2008$. Reconhecimento do vínculo empregatício que se impõe, ante a descaracterização do contrato de estágio alegado como fato impeditivo. (TRT-4 - RO: 00209620620175040004, Data de Julgamento: 13/05/2019, $2^{\text {a }}$ Turma).

E ainda:

RECURSO ORDINÁRIO DO RÉU. DIREITO INDIVIDUAL E PROCESSUAL DO TRABALHO. CONTRATO DE ESTÁGIO NULO. VÍNCULO DE EMPREGO. Nos termos da conceituação legal do art. $1^{\circ}$ da Lei $n^{\circ} 11.788 / 2008$, o estágio é ato educativo escolar supervisionado, desenvolvido no ambiente de trabalho, que visa à preparação para o trabalho produtivo de educandos. A relação de estágio ostenta todos os caracteres da relação de emprego, mas, por opção do legislador, considerando as necessidades de formação pedagógica e ingresso no mercado profissional, dá-se uma feição jurídica diversa, dependente das formalidades previstas na lei. A atipicidade da relação de estágio centra-se primordialmente nos objetivos do contrato, que não se satisfazem com o salário, mas dependem do aprendizado de competências próprias da atividade profissional e à contextualização curricular, conforme consta no art. $1^{\circ}$, $\S 2^{\circ}$, da Lei $n^{\circ} 11.788 / 2008$ e destaca a citação do autor. Nesse contexto, é que se devem interpretar as exigências formais constantes no art. $3^{\circ}$ da lei de estágio. Isto é, a apresentação dos documentos da lei de estágio tem por finalidade demonstrar a compatibilidade entre as atividades desenvolvidas no estágio e aquelas previstas no termo de compromisso e nesse contexto torna-se evidente a imprescindibilidade do relatório de estágio para se ter como válida a contratação dessa modalidade especial de relação de trabalho. Recurso a que se nega provimento. (Processo: RO - 0001669-30.2016.5.06.0101, Relator: Sergio Torres Teixeira, Data do Julgamento: 13/09/2018, Primeira Turma, Data da assinatura: 25/09/2018). (TRT-6 - RO: 00016693020165060101, Data de Julgamento: 13/09/2018, Primeira Turma).

Conforme se observa nos julgados acima, mesmo de diferentes tribunais, ambos tiveram o reconhecimento do vínculo empregatício devido a inobservância as cláusulas do termo de compromisso, descumprindo-as. O desvirtuamento do intuito pedagógico, caracterizando a relação de emprego, considera nulo o contrato de estágio. Nota-se no exposto da lei, que qualquer descumprimento ao termo de compromisso, pode acarretar em caracterização de vínculo empregatício. A responsabilidade pelo descumprimento do contrato de estágio é inclinado a parte concedente, por muitas vezes nos julgamentos, condenando-a quando apenas esta parte deu causa ao desvirtuamento, ou também de forma a condenar agentes de integração, por exemplo, por indicarem aos educandos serviços incompatíveis com o curso. Em caso de qualquer descumprimento a Lei do Estágio, a causa poderá ser anulada perante a Justiça do Trabalho, tendo visto a força do que há disposto no art. $9^{\circ}$ da Consolidação das Leis do Trabalho (CLT), 
caracterizando o vínculo de emprego, pela primazia da realidade. Em contrapartida, há também discussões e julgados nos quais não foi possível comprovar o vínculo de emprego, mantendo o contrato de estágio em seu teor, firmado pelo termo de compromisso, como exemplo as seguintes decisões dos tribunais:

CONTRATO DE ESTÁGIO. DESVIRTUAMENTO. NÃO OCORRÊNCIA. AFASTADO O RECONHECIMENTO DE VÍNCULO EMPREGATÍCIO. É tênue a linha que separa o contrato de estágio do contrato de trabalho. A diferença reside no objetivo educacional do estágio, que tem a finalidade de proporcionar ao aluno um aprendizado prático que possibilite o aperfeiçoamento da formação estudantil. In casu, à luz da prova produzida, não se pode afirmar, com segurança, tenha havido desvirtuamento do contrato de estágio, de sorte a permitir a aplicação do art. $9^{\circ}$ da CLT, com o consequente reconhecimento do vínculo empregatício. Recurso obreiro improvido, no ponto. (Processo: ROPS - 0000273-87.2018.5.06.0023, Redator: Jose Luciano Alexo da Silva. Data do julgamento: 18/07/2019. Quarta Turma. Data da assinatura: 18/07/2019). (TRT-6 - RO: 00002738720185060023, Data de Julgamento: 18/07/2019. Quarta Turma).

Da mesma forma, decidiu o TRT-2:

CONTRATO DE ESTÁGIO VALIDAMENTE FIRMADO. Preenchimento dos requisitos do art. $3^{\circ}$ da Lei $11.788 / 08$. Não há como reconhecer a nulidade do contrato de estágio, eis que validamente firmado o ato educativo supervisionado entre as partes, diante do cumprimento dos requisitos da Lei 11.788/08, quais sejam, a matrícula e frequência do estagiário em instituição de ensino, a assinatura de termo de compromisso com as partes envolvidas, a compatibilidade das atividades desenvolvidas com as descritas no termo e a supervisão do estágio. Recurso do reclamante a que se nega provimento. (TRT-2 00041044120145020203 Barueri - SP, Relator: MARIA DA CONCEIÇÃO BATISTA, Data de Julgamento: 04/04/2017, $5^{\text {a }}$ Turma, Data de Publicação: 07/04/2017).

O desvirtuamento do estágio ocorre a partir de um tomador de serviço que, de forma fraudulenta, descumpre as normas trabalhistas, e substituem a mão de obra necessária em sua empresa por estagiários, descumprindo o foco pedagógico que traz o termo de compromisso celebrado entre as partes. Para Delgado (2013, p. 328) "o contrato de estágio tem formalidades especiais, imperativas à sua configuração. Caso não atendidas tais formalidades (requisitos formais), descaracteriza-se a relação jurídica de estágio". Há muita discussão no domínio jurídico sobre este tema, com muitos entendimentos divergentes. Vale observar a linha tênue entre as relações de emprego e de estágio, ambas sendo empregadas como relação de trabalho, cada qual com sua característica e regulamento a seguir. 


\section{ANÁLISE DOS RESULTADOS}

Por muitos anos o estágio sofreu alterações em sua legislação, sendo mudanças ora favoráveis, ora prejudiciais ao estagiário, porém sempre ocorreu com o intuito de auxiliar as empresas oferecendo jovens educandos dispostos a colocar em prática seus estudos, além de proteger e garantir ao estudante melhores condições, conciliando as aulas e a prática. A atual Lei de Estágio busca ultrapassar o interesse da empresa, como principal parte da relação, colocando em evidência a necessidade relacionada a importância pedagógica da instituição de ensino, fixando o estágio como componente curricular.

Da mesma forma que a lei vigente traz benefícios e oportunidades aos estudantes, sua prática é confundida, habitualmente, com a relação de emprego. É estreito o entendimento referente a relação de emprego e relação de trabalho, contudo o contrato de estágio é relação de trabalho, apenas. De nenhuma forma pode ser ofertado ou tratado como emprego, conforme rege a Consolidação das Leis do Trabalho (CLT), para isto tem sua própria lei, vigente desde 2008 (lei $\mathrm{n}^{\circ}$ 11.788/2008).

A prática do estágio não pode ser confundida com a aplicação de mão de obra barata (incerta) a ser utilizada nas empresas. A legislação em vigor apresenta base jurídica para que o estágio permaneça vinculado a grade curricular das instituições de ensino. Não há dúvidas de que as atividades de estágio aproximam as relações de emprego, diferenciando o estagiário e o empregado apenas por suas formas, como a contraprestação de serviço, sendo a do estagiário bolsa ou outra contraprestação (para estágio não obrigatório, por exemplo), e do empregado o salário. Neste entendimento, Martinez (2012, p. 101-102) enaltece que:

\footnotetext{
O estagiário não é um "trabalhador" no sentido jurídico da palavra (conquanto muito se esforce para cumprir bem seus objetivos). Ele, na verdade, está sendo preparado para o "trabalho", mas, enquanto esse momento não chega, é simplesmente "exercente da atividade em sentido estrito". Por não ser juridicamente um trabalhador, o estagiário não tem jornada de trabalho, mas sim "jornada de atividade" (vide o art. 10 da mencionada lei $n^{\circ} 11.788 / 2008$ ); não tem férias, mas sim "recesso" (vide o art. 13); não é segurado obrigatório, mas apenas, se assim quiser, "segurado facultativo" ( $\$ 2^{\circ}$ do art. 12).
}

Contudo, por mais que se embaracem as relações, a finalidade do estagiário é a inserção ao âmbito profissional de forma pedagógica, ainda havendo situações em que se enquadrem os componentes da relação de emprego: pessoalidade, subordinação, continuidade e a contraprestação, de certa forma. A existência de uma proximidade entre o contrato de estágio e o vínculo 
empregatício, é confundida pela inobservância da legislação vigente, fazendo com que os educandos, na qualidade de estagiários, realizem atividades que não lhes competem, mediante mão de obra barata, distinto do que realmente deveriam fazer em cumprimento a grade curricular e em respeito ao termo de compromisso, celebrado entre as partes.

Ocorrendo isso, o estudante deixa de ser estagiário e passa a ser empregado, podendo requerer na Justiça do Trabalho o pagamento integral das verbas trabalhistas e contratuais, bem como, a indispensável anotação na sua CTPS. Beneficia-se na relação fraudulenta, a parte concedente do estágio, tendo visto que emprega em condições muito mais precárias e baratas, mão de obra qualificada, ao invés de arcar com os custos e tributos que um empregado venha a ter, tais como $13^{\circ}$ salário, terço constitucional, vale-transporte, salário mínimo obrigatório, pagamento de FGTS, dentre outros direitos que seria cabíveis ao trabalhador, no caso o estagiário na condição de empregado.

De acordo com a teoria de Vidotti (2004, p. 154) "a contratação de estagiário não deve ter por objetivo apenas o aproveitamento de mão-de-obra mais barata, sem pagamento de qualquer encargo social, mascarando a relação de emprego". O objetivo principal do estágio é o investimento no futuro profissional do estagiário. O estágio não é uma relação econômica, mas uma relação educacional, com fins pedagógicos. É certo que o estágio, quando realizado de maneira correta é uma oportunidade única de estudo e inserção em um mercado de trabalho cada vez mais exigente.

\section{CONSIDERAÇÕES FINAIS}

A relação entre estudante, empresa concedente do estágio e a instituição de ensino, formando uma tripartite, é regida pelos vínculos pedagógicos, ora mencionados na Lei 11.788/2008. Todos os requisitos previstos na legislação devem ser cumpridos para que não haja o desvirtuamento, expondo o estudante, na qualidade de estagiário, que passe a exercer atividades que não são condizentes ao seu curso e sua grade curricular. Ocorre a nulidade do contrato de estágio toda vez que a lei é fraudada, ou seja, quando não há supervisão no desempenho das atividades, usando o estagiário como máscara, de fato a encobrir uma verdadeira relação de emprego.

Quando há o descumprimento do contrato de estágio, esta nulidade deve ser reconhecida na esfera jurídica, ficando a cargo da parte concedente, por muitas vezes, assim condenada, ao 
pagamento das verbas trabalhistas, encargos sociais, anotações na carteira de trabalho, e dependendo da situação, até indenizações por danos morais e materiais. Todos que concorrerem ao descumprimento do contrato de estágio estão expostos a possíveis condenações, seja a parte concedente, a instituição de ensino ou os agentes de integração.

A fiscalização branda faz com que a lei em estudo não seja cumprida com rigor, sendo necessário recorrer à Justiça para garantir qualquer direito, conforme observou-se nos julgados dos tribunais regionais. Neste artigo pôde-se analisar o pensamento de alguns autores a respeito do tema, à luz da lei no 11.788/2008, confrontando a lei do estágio e a CLT, pautando as características de empregado e empregador, buscando afastar entendimentos que levam ao desvirtuamento do contrato de estágio. Posto isto, entende-se que por mais que exista uma lei que regulamente os contratos de estágio, há muitos desvirtuamentos a fim de facilitar os processos nas relações de trabalho, confundindo informações e não cumprindo com o devido.

Em virtude dos fatos mencionados, será necessário muito respeito das partes envolvidas às normas legais, para que a lei em estudo seja cumprida sem questionamentos, sendo uma grande oportunidade ao aluno se inserir ao mundo profissional. Buscando uma saída, vale citar e solicitar que o Ministério do Trabalho, como agente fiscalizador, atue de forma a combater qualquer fraude prejudicial ao plano pedagógico do contrato de estágio e sua lei. O contrato de estágio é uma oportunidade de trabalho ao educando e também oportunidade às empresas, para que conheçam a fundo o trabalho prático daqueles que coincidem teoria e exercício, contribuindo com o crescimento organizacional.

A lei $n^{\circ} 11.788 / 08$ expandiu a proteção ao estagiário, assegurando-lhe alguns direitos, que por ora são parecidos aos dos empregados, mas também implementou medidas para combater a fraudulentos e desvirtuados contratos de estágio. Por fim, para a lei ser eficaz deverá haver conscientização dos tomadores de serviço, para que não utilizem esta relação de forma fraudulenta, afim de baixar custos para a empresa, deixando de arcar com as despesas de um empregado, sendo o estagiário mão de obra mais barata.

É dever de qualquer parte denunciar. Em relação a fiscalização por parte do Ministério do Trabalho e Emprego, sem deixar de mencionar a responsabilidade do acordo tripartite, cabe a todas as partes ser responsável pelo zelo e cumprimento do contrato de estágio, à luz da lei $\mathrm{n}^{\circ}$ $11.788 / 2008$. 


\section{REFERÊNCIAS}

BRASIL. Lei $\mathbf{n}^{\mathbf{0}} \mathbf{1 1 . 7 8 8}$, de 25 de setembro de 2008. Dispõe sobre o estágio de estudantes; altera a redação do art. 428 da Consolidação das Leis do Trabalho - CLT, aprovada pelo Decreto-Lei no 5.452, de 1o de maio de 1943, e a Lei no 9.394, de 20 de dezembro de 1996; revoga as Leis nos 6.494, de 7 de dezembro de 1977, e 8.859, de 23 de março de 1994, o parágrafo único do art. 82 da Lei no 9.394, de 20 de dezembro de 1996, e o art. 6o da Medida Provisória n ${ }^{\circ} 2.164-41$, de 24 de agosto de 2001; e dá outras providências. Brasília, 2008.

BRASIL. Decreto Lei no 5.452: Aprova a Consolidação das Leis do Trabalho. Disponível em: < http://www.planalto.gov.br/ccivil_03/decreto-lei/del5452.htm>. Acesso em: 31 de Jul. de 2019.

DELGADO, Mauricio Godinho. Curso de direito do trabalho.12.ed. São Paulo: LTr, 2013.

GIL, Antônio Carlos. Métodos e técnicas de pesquisa social. 6. ed. São Paulo: Atlas, 2008.

JUSBRASIL. $2^{\circ}$ Grau. Tribunal Regional do Trabalho da $2^{\text {a }}$ Região TRT-2 - Recurso Ordinário: RO 0004104412145020203 - Inteiro Teor. Disponível em: https://trt2.jusbrasil.com.br/jurisprudencia/500114527/41044120145020203-barueri-sp/inteiro-teor500114537?ref=juris-tabs. Acesso em 25 jul. 2019.

JUSBRASIL. $2^{\circ}$ Grau. Tribunal Regional do Trabalho da $4^{\text {a }}$ Região TRT-4 - Recurso Ordinário: RO 00209620620175040004 - Inteiro Teor. Disponível em: https://trt4.jusbrasil.com.br/jurisprudencia/708781550/recurso-ordinario-ro-209620620175040004/inteiroteor-708781554?ref=serp. Acesso em: 25 de jul. 2019.

JUSBRASIL. $2^{\circ}$ Grau. Tribunal Regional do Trabalho da $6^{\text {a }}$ Região TRT-6 - Recurso Ordinário: RO 00002738720185060023 - Inteiro Teor. Disponível em: <https://trt6.jusbrasil.com.br/jurisprudencia/734203637/recurso-ordinario-em-procedimento-sumarissimoro-2738720185060023/inteiro-teor-734203647? ref=serp>. Acesso em 25 jul.

2019.

JUSBRASIL. $1^{\circ}$ Grau. Tribunal Regional do Trabalho da $6^{\text {a }}$ Região TRT-6 - Recurso Ordinário: RO 00016693020165060101 - Inteiro Teor. Disponível em: < https://trt6.jusbrasil.com.br/jurisprudencia/631625963/recurso-ordinario-ro-

16693020165060101 ?ref=serp>. Acesso em 31 jul. 2019.

MARTINEZ, Luciano. Curso de direito do trabalho: relações individuais, sindicais e coletivas de trabalho. 3.ed. São Paulo: Saraiva, 2012.

MINISTÉRIO DO TRABALHO E EMPREGO. Cartilha esclarecedora sobre a lei do estágio: lei 11.788/2008. Brasília, 2008.

NASCIMENTO, A. M.; NASCIMENTO, S. M. Iniciação ao direito do trabalho. 39.ed. São Paulo: LTr, 2014. 
VIDOTTI, Tárcio José. Introdução à Formação Técnico-Profissional: teoria geral, contrato de aprendizagem, estágio curricular. São Paulo: LTr, 2004. 